\title{
Development of a Novel Melt Spinning-Based Processing Route for Oxide Dispersion- Strengthened Steels
}

\author{
ZULIANG HONG, ALASDAIR P.C. MORRISON, HONGTAO ZHANG, \\ STEVE G. ROBERTS, and PATRICK S. GRANT
}

\begin{abstract}
Melt spinning of an Fe-5Y and Fe-1Y-1Ti (wt pct) alloy produced a relatively uniform spatial distribution of $\mathrm{Y}$ and $\mathrm{Ti}$ in solid solution and ribbons with consistent yield ( $>60$ pct by weight), fast processing time ( $<10$ seconds), good scalability (up to $>100 \mathrm{~g}$ feedstock material), and repeatability. Heat treatment in the presence of $\mathrm{Fe}_{2} \mathrm{O}_{3}$ as an oxygen source (Rhines pack method) at $973 \mathrm{~K}$ validated the potential of forming $<20 \mathrm{~nm}$ Y-rich oxides in the Fe-5Y ribbons. Pulverized Fe-1Y-1Y ribbons were consolidated to bulk using the field-assisted sintering technique (FAST) incorporating nano-sized $\mathrm{Fe}_{3} \mathrm{O}_{4}$ powder as the oxygen source. After FAST at $1273 \mathrm{~K}, 50 \mathrm{MPa}$, and 30 minutes, a comparatively high number density of sub-micron $\mathrm{Y}$ and/or Ti-rich oxides were developed. Further formation of fine-scale oxides took place during post-FAST annealing, resulting in an approximate 20 pct increase in hardness at temperatures below $573 \mathrm{~K}$, but with a reduced hardening effect above $673 \mathrm{~K}$ due to a small fraction of persistent porosity and mechanically weak prior ribbon boundaries that were decorated with Ti-rich oxides.
\end{abstract}

https://doi.org/10.1007/s11661-017-4398-x

(c) The Author(s) 2017. This article is an open access publication

\section{INTRODUCTION}

FERRITIC oxide dispersion-strengthened (ODS) steels that contain a high number density but low volume fraction of evenly distributed Y-, Ti-, and O-enriched nano-sized precipitates have emerged as one of the most promising structural material candidates for Generation IV fission and future fusion power plant concepts. ${ }^{[1-5]}$ The widely practiced processing route for these ODS steels is essentially a two-step powder metallurgy process, consisting of mechanical alloying (MA) of 10- to 90- $\mu$ m-diameter pre-alloyed Fe-based alloy powder together with a normally nano-sized (20 to $50 \mathrm{~nm}) \mathrm{Y}_{2} \mathrm{O}_{3}$ powder until fine-scale mixing/alloying is achieved, followed by consolidation of the powder into a bulk form typically by hot isostatic pressing (HIP) or related technique. ${ }^{[5-10]}$ This MA approach is now well optimized and convenient for laboratory-based studies, providing good quality material sufficient for detailed

ZULIANG HONG, ALASDAIR P.C. MORRISON, STEVE G. ROBERTS, and PATRICK S. GRANT are with Department of Materials, University of Oxford, Oxford, OX1 3PH, UK. Contact e-mail: zuliang.hong@gmail.com HONGTAO ZHANG is with the Department of Materials, Loughborough University, Leicestershire, LE11 3TU, UK.

Manuscript submitted April 24, 2017.

Article published online December 4, 2017 microscopy, irradiation, and mechanical property assessment. However, in technological terms, disadvantages of the MA route include prolonged processing time, small batch size, tendency for contamination associated with the high specific area of the powder, and the high inherent cost of the pre-alloyed feedstock powders, which combine to restrict wider commercial implementation of the MA-based route..$^{[1,11-16]}$

Thus, while key properties of ODS alloys, such as creep and irradiation resistance, are attractive, it is worthwhile to continue to explore alternative fabrication routes to replace/circumvent the MA process that might potentially achieve a higher throughput more suited for industrial production, probably with some, but acceptable, compromises in microstructure and mechanical properties. Recent efforts in this direction include in situ oxidation of a Y-containing melt during gas atomization, oxidation of a gas atomized Y-containing powder, and spray forming of a Y-containing melt. ${ }^{[7]}$ While providing some encouragement, so far none of these approaches have developed to the point that they may be considered likely as replacements for MA-based processing.

As a further alternative, melt spinning is explored in this study. Melt spinning involves non-equilibrium, high-speed solidification by rapid quenching of a molten alloy into a ribbon morphology of usually $<50 \mu \mathrm{m}$ thickness. ${ }^{[18]}$ Cooling rates above $10^{5} \mathrm{~K} / \mathrm{s}$ are generally 
quoted for melt spinning ${ }^{[18]}$ but solidification (solid/ liquid interface) velocity is a more meaningful description of the conditions under which the as-spun microstructure forms, and speeds $\gg 1 \mathrm{~mm} / \mathrm{s}$ are common. ${ }^{[19,20]}$ As the interface moves at these high speeds, thermodynamic equilibrium between liquid and solid phase compositions falters, and kinetic considerations dominate so that significant, elevated meta-stable concentrations of solute atoms can be "trapped" in solid solution. ${ }^{[18]}$ In this study, the hypothesis is that the normally near zero room temperature solubility of $\mathrm{Y}$ in $\mathrm{Fe}^{[21]}$ may be extended by melt spinning, and on subsequent heat treatment, the excess $\mathrm{Y}$ will precipitate and can simultaneously oxidize 'internally' to form a dispersion of Y-enriched oxides. Although melt spinning is also a batch process like MA, it is comparatively mature and has already been significantly scaled-up commercially and applied for the industrial production of amorphous ferromagnetic ribbons with a global capacity exceeding 100,000 t/ year. ${ }^{[2]}$ Although it is unlikely that a melt spinning-based route will produce the same microstructure as MA, sufficiently useful dispersion strengthening might still be achieved and any associated reduction in properties might be offset by the benefits of the scaled-up production capability.

Melt spinning followed by internal oxidation has previously been used as a potential route for the production of $\mathrm{Cu}$-based $\mathrm{ODS}$ alloys where nano-sized $(<100 \mathrm{~nm}) \mathrm{Y}_{2} \mathrm{O}_{3}$ particles were successfully formed in $\mathrm{Cu}-0.33$ wt pet $\mathrm{Y}$ ribbons after $1023 \mathrm{~K}$ at 3 hours. ${ }^{[23]}$ In comparison with MA routes, the particles were comparatively coarse and in agglomerated clusters, which will undermine their dispersion strengthening effect. ${ }^{[23]}$ In Fe-based ODS alloys, internal oxidation was confirmed as a viable option to generate nano-sized $\mathrm{Y}$-enriched oxides from bulk Fe-Y intermetallics such as $\mathrm{Fe}_{17} \mathrm{Y}_{2}$ and $\mathrm{Fe}_{11} \mathrm{TiY}$. ${ }^{[4]}$ However, in this case, a limiting factor was the comparatively slow diffusion of $\mathrm{O}$, which resulted in an up to $30 \mu \mathrm{m}$ oxide-containing external layer after 3 days at 873 and $973 \mathrm{~K}$. The Y-rich particles had both spherical and lamellar morphology and a range of compositions including $\mathrm{Y}_{2} \mathrm{O}_{3}, \mathrm{YFeO}_{3}$, $\mathrm{Y}_{2} \mathrm{Ti}_{2} \mathrm{O}_{7}$, and $\mathrm{Fe}_{2} \mathrm{TiO}_{4} \cdot{ }^{[24]}$

This study presents the development of a two-step melt spinning-based processing route for ODS steels. Fe-Y and Fe-Y-Ti alloys are rapidly solidified, followed by consolidation of the spun ribbons into bulk and simultaneous internal oxidation of any retained $\mathrm{Y}$ and/or $\mathrm{Ti}$ in solid solution into oxides, which are studied by various types of microscopy. Two alloys were studied: Fe-5Y (wt pct, MS01) with a comparatively high $\mathrm{Y}$ concentration to facilitate easy identification and study of any internal oxidation response, and Fe-1Y-1Ti (MS02) to confirm the scalability of melt spinning, to explore a more dilute composition closer to widely explored MA ODS steels, and to investigate the feasibility of internal oxidation during consolidation.

\section{EXPERIMENTAL}

For MS01, master alloy billets of approximately $10 \mathrm{~g}$ were produced by arc melting of $\mathrm{Fe}(<10 \mu \mathrm{m}, 99.9$ pct, Alfa Aesar) and Y $(<400 \mu \mathrm{m}, 99.6$ pct, Alfa Aesar $)$ powder using a Lincoln Electric Idealarc R3R 500-I arc melting furnace. For MS02, master alloy billets of approximately $120 \mathrm{~g}$ were produced by arc melting of $\mathrm{Fe}$ (99.97 pct, Alfa Aesar), Fe-33.1Y (wt pct, Goodfellow), and Ti (99.99 pct, Alfa Aesar) pieces using an Arcast Arc 200 arc melting furnace. The master alloy billets were flipped over each time between three re-melting cycles to promote elemental uniformity. Melt spinning of MS01 ( $6 \mathrm{~g}$ yield per run) was carried out at the Department of Materials, Oxford University, UK, using a $\mathrm{Cu}$ wheel rotating at a tangential velocity of $20 \mathrm{~m} / \mathrm{s}$, while the higher throughput MS02 production (up to $100 \mathrm{~g}$ yield per run) was conducted at the Fraunhofer IFAM, Dresden, Germany, using a $\mathrm{CuCr} 1 \mathrm{Zr}$ wheel operating at a tangential velocity of $40 \mathrm{~m} / \mathrm{s}$.

The Rhines pack method ${ }^{[25]}$ was used for internal oxidation studies of MS01 ribbons, which were packed inside a quartz tube with the similar weight of $\mathrm{Fe}_{2} \mathrm{O}_{3}$ powder ( $<325$ mesh, 99.5 pct, Alfa Aesar), separated by a porous quartz fiber wool, pumped to vacuum $\left(<1 \times 10^{-4} \mathrm{mbar}\right)$, sealed, and then heated to elevated temperatures ranging from 873 to $1473 \mathrm{~K}$ for 4 hours. For simultaneous consolidation and internal oxidation studies of the MS02 ribbons, they were firstly pulverized into $<5 \mathrm{~mm}$ flakes and then mechanically blended with 1.8 wt pct $\mathrm{Fe}_{3} \mathrm{O}_{4}$ powder (15 to $20 \mathrm{~nm}, 99.5$ pct, US Research Nanomaterials, Inc.) in order to produce an $\mathrm{O}$ source analogous to the Rhines pack approach. Pulverization and blending (not MA) was performed quickly $(<2$ hours in total) in a Fritsch P6 Pulverisette ball mill (150 rpm, 5:1 ball to ribbon weight ratio), and the resulting mixture was cold pressed in a glove box ( $\mathrm{Ar}$ filled) before consolidating into bulk using a Dr Fritsch DSP507 field-assisted sintering (FAST) machine with a 20-mm-diameter graphite die. FAST was carried out at $1273 \mathrm{~K}$ and $50 \mathrm{MPa}$ for 30 minutes using carefully controlled direct current (up to $1.2 \mathrm{kA}$ ) at relatively low voltage (up to $4 \mathrm{~V}$ ).

For comparison, Fe-14Cr-3W-0.2Ti (14WT) and Fe-14Cr-3W-0.2Ti-0.25 $\mathrm{Y}_{2} \mathrm{O}_{3}$ (14YWT), typical of ODS steels for nuclear applications, ${ }^{[10]}$ were also produced using pre-alloyed 14WT $(<150 \mu \mathrm{m}$, Aubert and Duval $)$ and $\mathrm{Y}_{2} \mathrm{O}_{3}$ (20 to $40 \mathrm{~nm}$, PI-KEM Ltd.) powders and conventional MA-based processing. The raw materials were MA'ed using a Fritsch P5 Pulverisette ball mill (60 hours, $250 \mathrm{rpm}, 10: 1$ ball to powder weight ratio), followed by hot isostatic pressing into bulk at $1423 \mathrm{~K}$ and $150 \mathrm{MPa}$ for 4 hours. Note that unlike the melt spinning alloys where compositional simplicity was favored in order to study the $\mathrm{Fe}(\mathrm{Y})$ solid solution and subsequent precipitation behavior of excess Y, the MA alloys had more typical compositions, with significant $\mathrm{Cr}$ and $\mathrm{W}$ additions for solid solution strengthening and oxidation resistance. 
In summary, the first step was to validate the melt spinning process for a model Fe-Y alloy with a non-typical high concentration of $5 \mathrm{wt}$ pet chosen to (i) account for evaporative/reactive loss of $\mathrm{Y}$ that is well-known in the foundry industry, and (ii) to ensure any resulting $\mathrm{Y}$-rich oxides could be readily resolved without the need to use time-consuming, very high resolution microscopy techniques. At this stage, downstream consolidation was not needed, and only small $\sim 10 \mathrm{~g}$ melt charges were investigated. With promising results from melt spinning and internal oxidation of the Fe-5Y alloy, larger scale ( $100 \mathrm{~g}$ per run) and $\mathrm{Y}$ concentrations of $1 \mathrm{wt}$ pct, closer to those in typical ODS steels, were investigated, along with Ti additions to explore its potential refining effects on Y-based oxides, i.e., the alloy composition Fe-1Y-1Ti (wt pct). The slightly higher concentrations were used here again to account for evaporative loss during melting, and to ensure a resolvable fraction of any in situ-formed Y-based oxides. These larger-scale melt spinning experiments also produced enough materials for FAST sintering. The 14YWT alloy produced by conventional MA was chosen because it is typical of the ODS steel literature, and provided a useful baseline of properties.

Scanning electron microscopy (SEM) characterization was performed in a Zeiss EVO and a JEOL 6500F with a field emission gun (FEG), both operating at $20 \mathrm{kV}$, while transmission electron microscopy (TEM) characterization was conducted in a JEOL 3000F with a FEG operating at $300 \mathrm{kV}$. TEM foils were prepared based on a focused ion beam (FIB) lift-out technique ${ }^{[26]}$ in a Zeiss Auriga FEG-SEM/FIB dual beam microscope. X-ray diffraction (XRD) was carried out using a Siemens D5000 X-ray diffractometer, which operated at $40 \mathrm{kV}$ and $30 \mathrm{~mA}$ using a Ni-filtered $\mathrm{Cu} \mathrm{K} \alpha$ radiation source with a wavelength of $0.154184 \mathrm{~nm}$. Hot microhardness tests were conducted using a sapphire indenter with 200 $\mathrm{g}$ load and 20 seconds dwell time at $<1 \times 10^{-4} \mathrm{mbar}$ vacuum. Seven measurements were performed for each condition.

\section{RESULTS AND DISCUSSION}

The MS01 ribbons were 1 to $5 \mathrm{~cm}$ in length, 1.5 to 2.0 $\mathrm{mm}$ in width, and 20 to $30 \mu \mathrm{m}$ in thickness. The cross-section backscattered (BSE) SEM micrograph in Figure 1(a) shows the ribbon had a typical melt-spun microstructure comprising an almost featureless zone close to the cold $\mathrm{Cu}$ wheel in which sub-micron equiaxed grains were occasionally resolved. ${ }^{[27]}$ The solidification speed can be assumed to be the highest in this zone, with solid/liquid interface moving quickly from the cold wheel side through the ribbon. Further away from the chill surface, heat conduction through the ribbon itself and in particular the release of the latent heat of fusion from the previously solidified regions reduced the solidification rate so that a zone of fine columnar grains developed, growing against the predominantly one-dimensional heat flow, eventually transitioning into a third zone of larger (several $\mu \mathrm{m}$ ) equiaxed grains with dendritic structure towards the upper free surface of the ribbon. The relatively flat contrast in the BSE SEM micrograph for most of the ribbon thickness suggested a relatively uniform $\mathrm{Y}$ distribution, apart from some possible fine-scale, inter-dendritic segregation in the slowest solidifying regions towards the upper free surface. Area energy dispersive X-ray spectroscopy (EDX) measurements showed a relatively consistent Y concentration of 4.2 to $4.6 \mathrm{wt}$ pct across the thickness of the ribbon, and an $\sim 10$ pct loss of $\mathrm{Y}$ associated with the melting and dispensing process. Loss of reactive rare earths is common in liquid processing of $\mathrm{Fe}$ - and Ni-based alloys and the loss here was considered typical for this type of process. Although low $\mathrm{O}$ pick-up was also suggested, quantification by EDX was considered comparatively inaccurate and $\mathrm{O}$ concentrations should be treated with caution. ${ }^{[28]}$ These results provided encouragement that a relatively uniform $\mathrm{Y}$ distribution in solid solution with Fe, without excessive microsegregation at the micron-scale, could be achieved by melt spinning, with a tolerable loss of $\mathrm{Y}$.

MS01 ribbons were heat treated for $4 \mathrm{~h}$ at temperatures ranging from 873 to $1473 \mathrm{~K}$ in the Rhines pack arrangement. At $873 \mathrm{~K}$, there was little change in the microstructure over 4 hours, while at $1073 \mathrm{~K}$ and above there was excessive surface oxidation of the ribbon and grain growth. Heat treatment at $973 \mathrm{~K}$ produced the most encouraging response. As shown in Figure 1(b), the original three zone cross-sectional microstructure of the ribbons was largely homogenized at $973 \mathrm{~K}$, with darker contrast 'trails' across the surface due to preferential etching and pull-out of small particles along some of the grain boundaries during sample preparation. EDX measurements from typical regions of the ribbon cross-section gave $\mathrm{Y}$ concentrations (red) of 4.6 to $4.9 \mathrm{wt}$ pct and $\mathrm{O}$ (blue) of perhaps 1 to $1.2 \mathrm{wt}$ pct, noting the likely lower accuracy of the $\mathrm{O}$ measurements. ${ }^{[28]}$ Qualitatively by comparison with Figure 1(a), heat treatment led to a significant increase in $\mathrm{O}$ concentration in the ribbon. As can be expected, a near continuous $\mathrm{Fe}$ - and $\mathrm{Y}$-containing surface oxide layer of up to $1.5 \mu \mathrm{m}$ thickness also formed on the ribbons (labeled by the yellow dashed circles), indicating some $\mathrm{Y}$ diffusion towards the ribbon surface where $\mathrm{O}$ partial pressure was the highest.

The scanning TEM (STEM) high-angle annular dark-field (HAADF) image in Figure 1(c) shows that after $4 \mathrm{~h}$ at $973 \mathrm{~K}$ the ribbon had a refined microstructure consisting of $<200 \mathrm{~nm}$ grains, and a high number density and relatively uniform distribution of $<20 \mathrm{~nm}$ particles. There was no significant size variation between inter and intragranular particles, and the particle size histogram in the inset figure of Figure 1(c) based on 650 manual measurements shows a unimodal size distribution, with more than three-quarters of the particle diameters between 5 and $15 \mathrm{~nm}$. The higher-magnification STEM HAADF micrograph shown in Figure 1(d) and corresponding EDX measurements further confirmed a comparatively high number density of particles, which were enriched in Y and O. Selected area diffraction (SAD) covering an area $>3 \mu \mathrm{m}^{2}$ given in Figure 1(e) shows patterns that match well with simulated diffractions rings of bcc $\mathrm{Fe}$ (blue lines, PDF: 


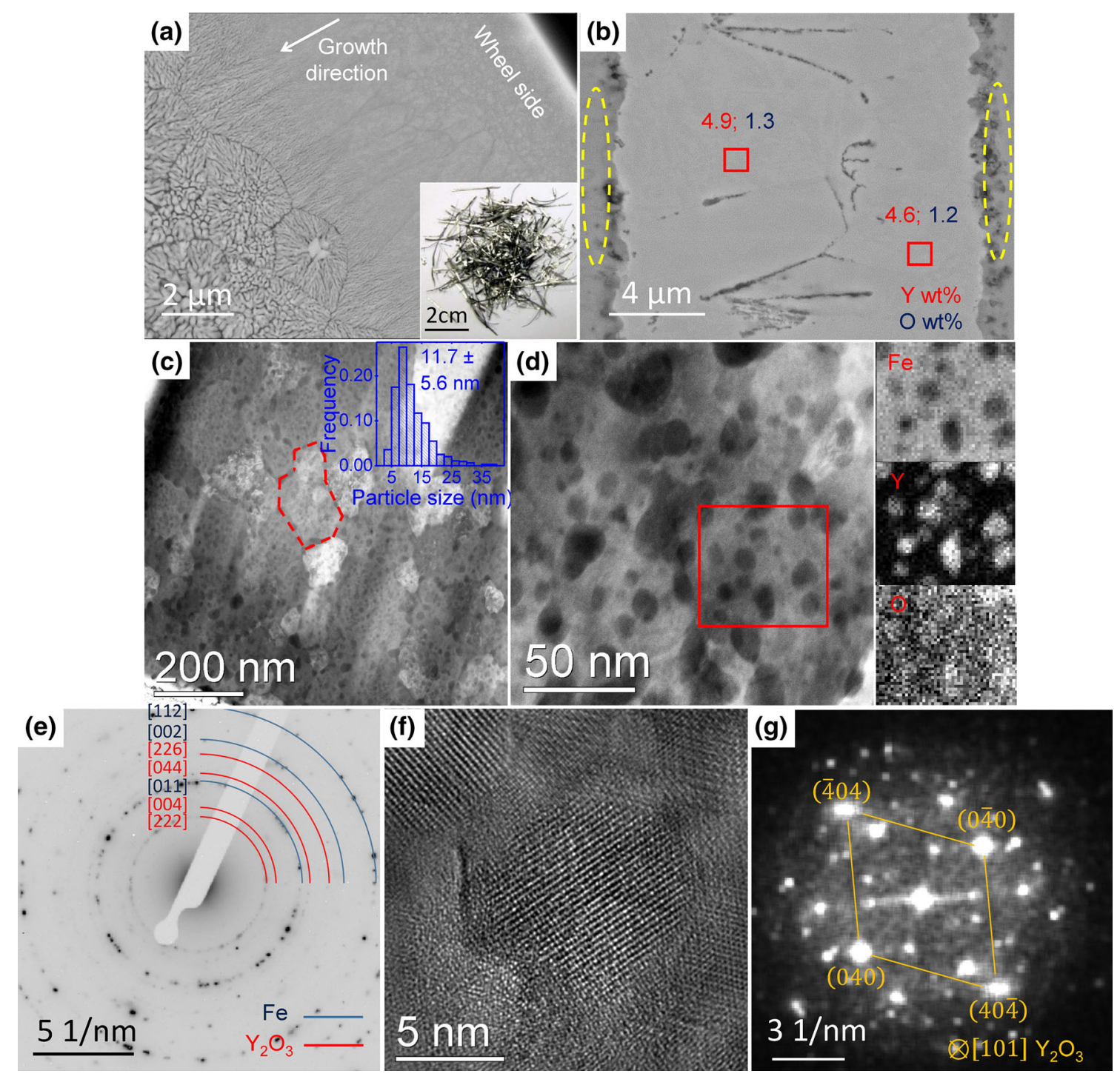

Fig. 1-SEM characterization of the MS01 ribbon in cross-section. (a) BSE micrograph with inset image of the as-spun ribbon, (b) BSE micrograph of the MS01 ribbon after $4 \mathrm{~h}$ at $973 \mathrm{~K}$ in a Rhines pack arrangement with $\mathrm{Y}$ (red) and $\mathrm{O}$ (blue) concentrations labeled in rectangles and the surface oxide layer highlighted in yellow dashed circles. TEM characterization of the MS01 ribbon after $4 \mathrm{~h}$ at $973 \mathrm{~K}$, (c) low-magnification STEM HAADF micrograph with red dashed lines highlighting a grain, and particle size histogram in inset, $(d)$ high-magnification STEM HAADF micrograph with inset EDX elemental maps of Fe, Y, and O from the red rectangle area, $(e)$ SAD pattern, $(f)$ HRTEM image of a small in-grain particle, and $(g)$ its corresponding FFT image and crystallographic analysis (Color figure online).

00-006-0696) and cubic $\mathrm{Y}_{2} \mathrm{O}_{3}$ (red lines, PDF: 01-071-0049). The HRTEM image (Figure 1(f)) and its FFT analysis (Figure $1(\mathrm{~g})$ ) of a single $<10$-nm-diameter $\mathrm{Y}$ - and $\mathrm{O}$-enriched particle confirmed a cubic $\mathrm{Y}_{2} \mathrm{O}_{3}$ structure oriented along the $\left[\begin{array}{lll}1 & 0 & 1\end{array}\right]$ zone axis. ${ }^{[29]}$ The additional spots in Figure 1(g) arose from the Fe matrix as well as likely other fine-scale Y-O and/or Y-Fe-O particles in a variety of different orientations, as can be seen in Figure 1(f).

With encouraging results from melt spinning and internal oxidation of the MS01 ribbons, MS02 ribbons were produced with 15 times higher throughput, reduced $\mathrm{Y}$ concentration, and addition of $\mathrm{Ti}$ that is known to produce a refining effect of Y-rich oxides in mechanical alloying. ${ }^{[30-32]}$ As shown in Figure 2(a), MS02 ribbons had a thickness of approximately $25 \mu \mathrm{m}$, which was comparable with the smaller-scale MS01 ribbons. However, there were now resolvable micron-sized equiaxed grains at the wheel side, and again largely featureless columnar grains growing against the 1D heat flow, and then a region of a more obvious microsegregation and dendritic structure towards the free side. The slightly coarser microstructure compared with MS01 was probably caused by a reduced cooling ability due to the higher total heat input into the wheel and the use of a larger slot in the dispensing nozzle that increased the melt flow rate onto the wheel. The corresponding EDX elemental maps in Figures 2(b) and (c) again demonstrate a relatively uniform distribution of $\mathrm{Y}$ and $\mathrm{Ti}$ and the sum spectrum showed $\mathrm{Y}$ and $\mathrm{Ti}$ concentrations of 

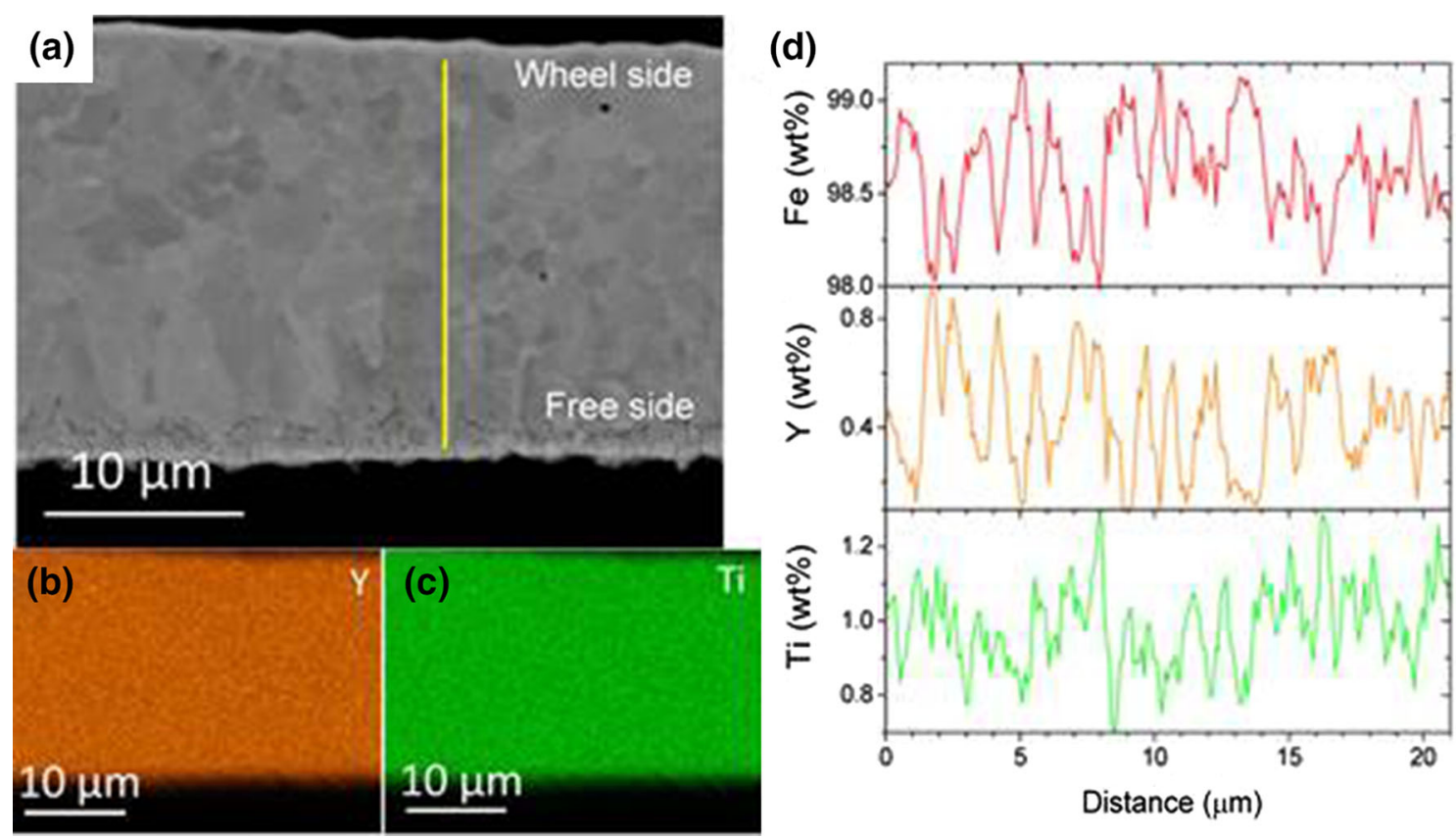

Fig. 2-SEM characterization of the MS02 ribbon in cross-section. (a) BSE micrograph with corresponding EDX elemental maps showing distributions of $(b) \mathrm{Y}$ and $(c)$ Ti. The yellow line in $(a)$ shows an EDX line scan across the ribbon thickness with the corresponding Fe, $\mathrm{Y}$, and Ti concentrations as a function of distance plotted in $(d)$ (Color figure online).
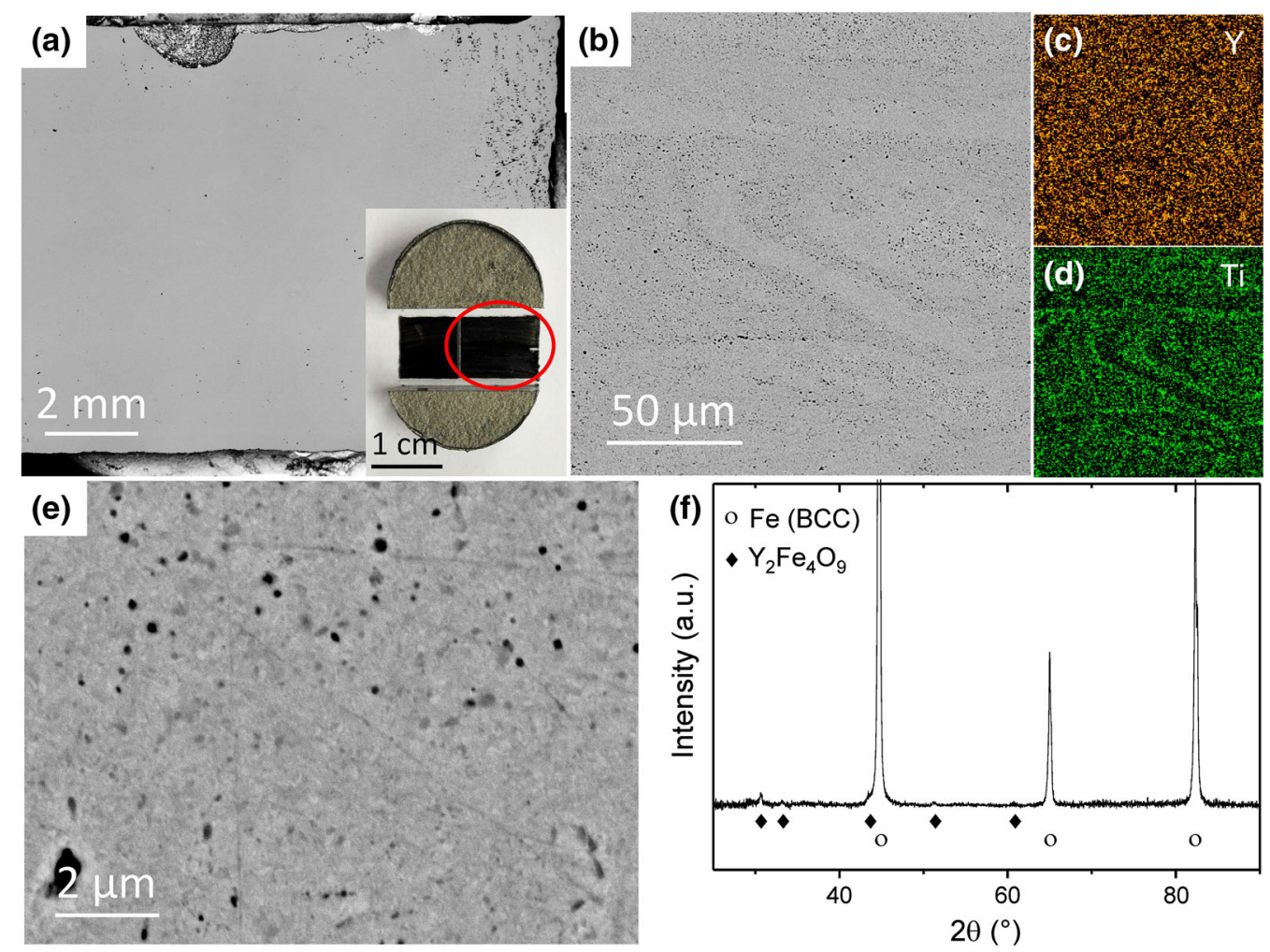

Fig. 3-SEM characterization of the as-consolidated Fe-1Y-1Ti billet. (a) Composite low-magnification BSE micrograph with inset image of the FAST cross-sectioned billet; $(b)$ BSE micrograph showing the layered structure with corresponding EDX elemental maps of $(c) \mathrm{Y}$ and $(d)$ Ti, $(e)$ BSE micrograph showing sub-micron particles; and $(f)$ XRD spectrum showing peaks corresponding to $\mathrm{BCC}_{\mathrm{Fe}}$ and $\mathrm{Y}_{2} \mathrm{Fe}{ }_{4} \mathrm{O}_{9}(\mathrm{PDF}$ : 00-044-1067). 


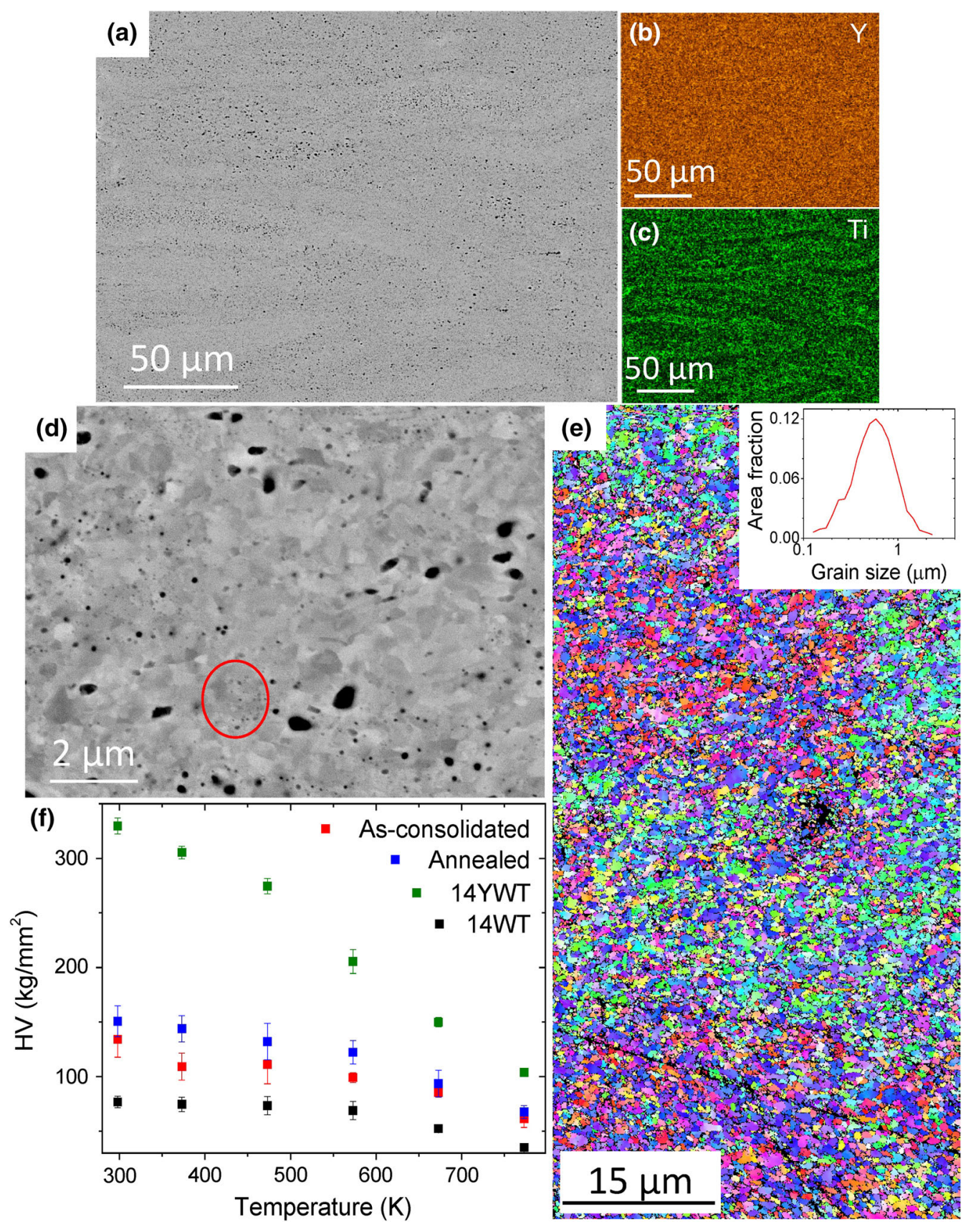

Fig. 4 - SEM characterization of the annealed Fe-1Y-1Ti billet. (a) BSE micrograph showing layered structure with corresponding EDX elemental maps of $(b) \mathrm{Y}$ and $(c) \mathrm{Ti}$; $(d)$ BSE micrograph showing sub-micron particles and possible regions containing $<20 \mathrm{~nm}$ particles in the red circle; (e) EBSD inverse pole figure map with inset grain size distribution; and $(f)$ microhardness of the as-consolidated and annealed Fe-1Y-1Ti billet from $298 \mathrm{~K}$ to $773 \mathrm{~K}$.

approximately $0.6 \pm 0.04$ and $1.0 \pm 0.02 \mathrm{wt}$ pct, respectively. These concentrations were consistent with the $\mathrm{Y}$ and $\mathrm{Ti}$ concentrations measured from EDX line scans taken across the thickness of the ribbon shown in Figure 2(d). Although concentration fluctuations suggested some inter-dendritic (micro-)segregation, the MS02 ribbon showed that both $\mathrm{Y}$ and $\mathrm{Ti}$ could be retained at useful concentrations by melt spinning at a higher flow rate, with only limited microsegregation and no formation of discrete intermetallic phases.
The MS02 ribbons were pulverized, blended with the $\mathrm{Fe}_{3} \mathrm{O}_{4}$ powder, and consolidated into a small billet of approximately $2 \mathrm{~cm}$ in diameter and $8 \mathrm{~mm}$ in thickness. The composite low-magnification BSE SEM micrograph of a cross-section across a diameter of the consolidated billet in Figure 3(a) reveals $>10-\mu$ m-diameter pores, which were primarily concentrated towards the radial edge of the cylindrical billet, in a layer of up to $1.7 \mathrm{~mm}$ thickness. Reduced consolidation at the periphery of billets has been reported for other FAST materials and 
arises from the inevitable diffusion of carbon from the graphite die and the resulting hardening (and increase in flow stress) of the alloy in this near-surface region. ${ }^{[33,34]}$ Alternatively, restricted heating due to lower local current density and heat losses to the graphite die have also been suggested to inhibit peripheral consolidation. ${ }^{[35,36]}$ Nevertheless, most of the small billet was significantly consolidated with overall only a small fraction $(<0.5 \mathrm{pct})$ of pores remaining. The higher-magnification BSE SEM micrograph in Figure 3(b) shows the interior regions of the consolidated billet had a layered structure, indicated by contrast variations that arose due to differences in the particle number density of different layers. Since the thickness of each layer approximated to the MS02 initial ribbon thickness, the layers were interpreted to represent persistence of the prior ribbon structure. Although almost all the particles were smaller than $1 \mu \mathrm{m}$, particles larger than $300 \mathrm{~nm}$ were particularly prevalent in the comparatively high particle number density layers. The channeling contrast BSE SEM micrograph in Figure 3(e) shows that the consolidated alloy had a nanocrystalline grain structure, with $<50 \mathrm{~nm}$-diameter grains just resolvable.

The EDX elemental maps in Figures 3(c) and (d) show that the higher particle number density regions contained many particles enriched in $\mathrm{Ti}$, while $\mathrm{Y}$ was distributed relatively homogeneously. Because both Y and $\mathrm{Ti}$ in solution of the MS02 ribbons were relatively uniformly distributed, the results may suggest that $\mathrm{Y}$ was a relatively sluggish diffuser under the conditions of temperature and time (thermal exposure) in the FAST consolidation. As the faster $\mathrm{Ti}$ diffused to the prior ribbon boundary, oxides were nucleated in this region, growing to $>300 \mathrm{~nm}$ diameter and were comparatively Ti-rich and Y-poor. The growth of these Ti-rich oxides also drew $\mathrm{Ti}$ from adjacent regions and produced a Ti-depleted zone near the interfaces between the prior ribbon boundaries. The faster diffusion of Ti than $\mathrm{Y}$ was consistent with studies on ODS steels produced by conventional ${ }^{[34]}$ and novel ${ }^{[17]}$ powder processing routes, where $\mathrm{Ti}$ enrichment was reported on prior particle boundaries.

The sum spectrum of the EDX elemental maps suggested approximate $\mathrm{Y}$ and $\mathrm{Ti}$ concentrations of $0.8 \pm 0.04$ and $1.0 \pm 0.02 \mathrm{wt}$ pct, respectively, showing good retention of both elements in the MS02 ribbons after heat treatment, while an elevated $\mathrm{O}$ concentration of approximately $1.1 \mathrm{wt}$ pct arose from the intended interaction with the $\mathrm{Fe}_{3} \mathrm{O}_{4}$, added as the $\mathrm{O}$ source, along with any unintended contamination during handling and processing. The XRD spectrum in Figure 3(f) showed peaks corresponding to $\mathrm{BCC} F$ (PDF: 00-006-0696) and weak, just resolvable peaks that were suggested to fit to $\mathrm{Y}_{2} \mathrm{Fe}_{4} \mathrm{O}_{9}$ (PDF: 00-044-1067) although unambiguous identification was not possible due to the weak reflections. There was no evidence of $\mathrm{Ti}$, or $\mathrm{Y}_{x} \mathrm{Ti}_{y}$ intermetallics in the consolidated alloy, and $\mathrm{Y}$ and $\mathrm{Ti}$ distributions were always preferentially associated with $\mathrm{O}$. There was also no evidence for residual $\mathrm{Fe}_{3} \mathrm{O}_{4}$ nanoparticles suggesting that they were either completely reduced by the preferential oxidation of $\mathrm{Y}$ and/or $\mathrm{Ti}$, or were remained at a fraction and length-scale that could not be resolved.

A section of the consolidated billet was vacuum-annealed $\left(<1 \times 10^{-4}\right.$ mbar $)$ at the previously identified optimal internal oxidation condition of $973 \mathrm{~K}$ for 4 hours, to investigate any incomplete, ongoing reactions between $\mathrm{Y}, \mathrm{Ti}$, and $\mathrm{O}$ after the relatively fast (but higher temperature) FAST processing. As shown in Figure 4(a), the layered structure persisted after annealing with particle number density variations similar to the as-consolidated state. The oxide particles were stable and no significant growth of the particle diameters was measured. However, Figure 4(d) reveals the possible formation of a new population of fine $(<20 \mathrm{~nm})$ particles (highlighted by the red circle), probably due to ongoing precipitation/oxidation of residual $\mathrm{Y}$ and Ti. It was difficult to ensure constant imaging conditions between samples and it is possible these particles may have been easier to resolve in this particular specimen. Part of the BSE channeling contrast image in Figure 4(d) also shows grain sizes of hundreds of nanometres, which were coarser than by FAST alone. These grains were investigated further by SEM electron backscatter diffraction (EBSD) over an area of 40 × $80 \mu \mathrm{m}$ with a step size of $80 \mathrm{~nm}$. The false colored EBSD inverse pole figure (IPF) map in Figure 4(e) suggested that the columnar, through-thickness orientation of as-spun grains in MS02 had largely disappeared and was replaced with a recovered polygonal sub-micron grain structure in the annealed condition. Nonetheless, within regions with thicknesses approximating to the MS02 ribbon thickness, some preferred orientation (predominantly green or pink) of grains persisted, presumably deriving from the prior through-thickness texture of the as-solidified columnar grains.

Assuming near-spheroidal grains, the grain size distribution was unimodal with a mean diameter of $620 \mathrm{~nm}$ and a standard deviation of $210 \mathrm{~nm}$. Unlike ODS steels produced by conventional MA-based processing, abnormal grain growth was not observed. ${ }^{[8,9,37-39]}$ It was not possible to confirm the exact reason for the comparative homogeneity of grain size but a likely factor may be the higher (up to four times) $\mathrm{Y}$ and Ti concentrations in the ribbons compared with typical ODS steels, ${ }^{[8,9,37-39]}$ producing a higher fraction of $\mathrm{Y}$ - and/or Ti-enriched oxides that pin grain growth during consolidation. This hypothesis is consistent with investigations of increasing the $\mathrm{Y}_{2} \mathrm{O}_{3}$ fraction from 0.2 to $0.8 \mathrm{wt}$ pct in an ODS steel produced by conventional MA-based processing, ${ }^{[40]}$ which increased the pinning oxide fraction and approximately halved the proportion of $\mu \mathrm{m}$-sized coarse grains. Since the recovery and recrystallization of ODS steels is determined by the balance between the driving force dominated by stored energy of cold work and the retarding force exerted by the $\mathrm{Y}$ - and/or Ti-enriched oxides, ${ }^{[39,41,42]}$ another possible factor for the relatively homogeneous grain size distribution in the annealed alloy may be the lower amount of work hardening for the pulverized melt-spun ribbons compared with conventional MA powder, which reduced the driving force for recrystallization and grain growth at elevated temperature during consolidation. 
Comparing with the as-consolidated state, the EDX elemental maps in Figures 4(b) and (c) show that the Ti in the annealed alloy was similarly concentrated into layers of relatively high particle number density, and the overall Y, Ti, and $\mathrm{O}$ concentrations approximated from the sum spectrum remained approximately constant.

Figure 4(f) shows the overall effect of annealing the as-consolidated Fe-1Y-1Ti alloy was an approximately 20 pct increase in hardness at temperatures below 573 $\mathrm{K}$, despite the increased grain sizes. This may support the earlier suggestion that annealing helps complete the reactions between $\mathrm{Y}, \mathrm{Ti}$, and $\mathrm{O}$, and the formation of the dispersion strengthening nano-sized particles. However, the hardness advantage of the annealed alloy disappeared at temperatures above $673 \mathrm{~K}$, which suggested that residual porosity and weak prior ribbon boundaries decorated with oxides may dominate hardness at higher temperatures. Comparing these hardnesses with those measured for a mechanically alloyed and solid-solution-strengthened reference 14WT alloy (no ODS particles), the annealed Fe-1Y-1Ti had approximately twice the hardness over the temperature range, suggesting that the in situ oxide formation had a significant effect on hardness. However, annealed Fe-1Y-1Ti had only approximately half the hardness of a mechanically alloyed 14YWT ODS steel. ${ }^{[43-46]}$ Although the dispersion of oxide particle diameters of 20 to $300 \mathrm{~nm}$ produced by melt spinning and internal oxidation route were coarser than the 1- to 5-nm-diameter oxides achievable by mechanical alloying under optimum conditions, there is sufficient encouragement to suggest future work might focus on melt spinning of more standard Fe-14Cr-3W-based alloys, with lower concentrations of $\mathrm{Y}$ and $\mathrm{Ti}$, and that with further optimization of heat treatment conditions, an alloy that provides useful performance with improved availability in bulk might be developed.

\section{CONCLUSIONS}

Rapidly solidified melt-spun ribbons of Fe-Y alloys showed significant extensions of solid solubility of $Y$ in $\mathrm{Fe}$, at both laboratory and intermediate scales. Fe-5Y ribbons were heat treated under vacuum with an oxygen source in a Rhines pack arrangement at temperatures between 873 and $1473 \mathrm{~K}$ for 4 hours. At $873 \mathrm{~K}$ there was little evidence for precipitation and oxidation of $\mathrm{Y}$ and/ or $\mathrm{Y} / \mathrm{Ti}$ containing oxides, while at $1073 \mathrm{~K}$ and above, excessive ribbon surface oxidation and large internal oxides formed. At $973 \mathrm{~K}$, a high number density of $<20$ nm Y-rich oxides formed, with some microstructural similarities to conventional ODS alloys. When Fe-1Y-1Ti as-spun ribbons were blended with $\mathrm{Fe}_{3} \mathrm{O}_{4}$ nano-powder as an oxygen source and consolidated by field-assisted sintering at $1273 \mathrm{~K}, 50 \mathrm{MPa}$, and 30 minutes, the simultaneous precipitation and internal oxidation of super-saturated $\mathrm{Y}$ and Ti again generated a high number density of sub-micron Y- and/or Ti-enriched oxides, but with persistence of prior ribbon boundaries delineated by relatively Ti-rich oxides. Further oxide particles formed on subsequent annealing at
$973 \mathrm{~K}$ along with some limited grain growth to an average grain diameter of $620 \mathrm{~nm}$. Although there was a small adverse impact of porosity and oxide-rich prior ribbon boundaries on hardness at higher temperatures, useful dispersion strengthening was generated with hardnesses approximately half of typical ODS steels fabricated by mechanical alloying. This initial study provides encouragement for further investigation of melt processing and internal oxidation approaches for ODS alloy production.

\section{ACKNOWLEDGMENTS}

The authors would like to thank the UK Engineering and Physical Sciences Research Council for financial support through grant awards EP/P001645/1 and EP/P006566/1, and Mr Andreas Schmidt from Fraunhofer IFAM, Branch Lab Dresden, for his help with melt spinning.

\section{OPEN ACCESS}

This article is distributed under the terms of the Creative Commons Attribution 4.0 International License (http://creativecommons.org/licenses/by/4.0/), which permits unrestricted use, distribution, and reproduction in any medium, provided you give appropriate credit to the original author(s) and the source, provide a link to the Creative Commons license, and indicate if changes were made.

\section{REFERENCES}

1. S. Ohtsuka, S. Ukai, M. Fujiwara, T. Kaito, and T. Narita: $J$. Phys. Chem. Solids, 2005, vol. 66, pp. 571-75.

2. D.L. Smith, M.C. Billone, S. Majumdar, R.F. Mattas, and D.K. Sze: J. Nucl. Mater., 1998, vols. 258-263, pp. 65-73.

3. S.J. Zinkle and J.T. Busby: Mater. Today, 2009, vol. 12, pp. 12-19.

4. S.J. Zinkle and G.S. Was: Acta Mater., 2013, vol. 61, pp. 735-58.

5. G.R. Odette, M.J. Alinger, and B.D. Wirth: Annu. Rev. Mater. Res., 2008, vol. 38, pp. 471-503.

6. S. Ukai, T. Nishida, T. Okuda, and T. Yoshitake: J. Nucl. Mater., 1998, vols. 258-63, pp. 1745-49.

7. S. Ukai and M. Fujiwara: J. Nucl. Mater., 2002, vols. 307-11, pp. 749-57.

8. M.A. Auger, V. De Castro, T. Leguey, A. Munoz, and R. Pareja: J. Nucl. Mater., 2013, vol. 436, pp. 68-75.

9. H. Zhang, Y. Huang, H. Ning, C.A. Williams, A.J. London, K. Dawson, Z. Hong, M.J. Gorley, C.R.M. Grovenor, G.J. Tatlock, S.G. Roberts, M.J. Reece, H. Yan, and P.S. Grant: J. Nucl. Mater., 2015, vol. 464, pp. 61-68.

10. M.J. Alinger, G.R. Odette, and D.T. Hoelzer: Acta Mater., 2009, vol. 57, pp. 392-406.

11. C. Heintze, M. Hernández-Mayoral, A. Ulbricht, F. Bergner, A. Shariq, T. Weissgärber, and H. Frielinghaus: J. Nucl. Mater., 2012, vol. 428, pp. 139-46.

12. T. Narita, S. Ukai, S. Ohtsuka, and M. Inoue: J. Nucl. Mater., 2011, vol. 417, pp. 158-61.

13. R. Vijay, M. Nagini, J. Joardar, M. Ramakrishna, A.V. Reddy, and G. Sundararajan: Metall. Mater. Trans. A, 2012, vol. 44A, pp. 1611-20.

14. M. Brocq, B. Radiguet, S. Poissonnet, F. Cuvilly, P. Pareige, and F. Legendre: J. Nucl. Mater., 2011, vol. 409, pp. 80-85. 
15. Z. Oksiuta, M. Lewandowska, P. Unifantowicz, N. Baluc, and K.J. Kurzydlowski: Fusion Eng. Des., 2011, vol. 86, pp. 2417-20.

16. C. Suryanarayana: Prog. Mater. Sci., 2001, vol. 46, pp. 1-184.

17. F. Bergner, I. Hilger, J. Virta, J. Lagerbom, G. Gerbeth, S. Connolly, Z. Hong, P.S. Grant, and T. Weissgärber: Metall. Mater. Trans. A Phys. Metall. Mater. Sci., 2016, vol. 47, pp. 5313-24.

18. N.B. Dahotre, R. Asthana, and A. Kumar: Materials Processing and Manufacturing Science, Academic Press, London, 2006, pp. $157-59$

19. S.C. Huang, R.P. Laforce, A.M. Ritter, and R.P. Goehner: Metall. Mater. Trans. A, 1985, vol. 16A, pp. 1773-79.

20. R. Willnecker, D.M. Herlach, and B. Feuerbacher: Phys. Rev., 1989, vol. 62, pp. 2707-10.

21. B.W. Zhang, G. Liu, and K. Han: J. Phase Equilib., 1992, vol. 13, pp. 304-08.

22. P.C. Ryan: Comments from Hitachi Metals America Ltd. and Metglas Inc. regarding the ENERGY STAR transformer program (Energy star, 2015) https:/www.energystar.gov/sites/default/files/ Hiatchi-MetglasComments.pdf. Accessed 7 Sept 2016.

23. M.S. Nagorka, C.G. Levi, and G.E. Lucas: Metall. Mater. Trans. A, 1995, vol. 26A, pp. 860-71.

24. J.H. Schneibel and S. Shim: Mater. Sci. Eng. A, 2008, vol. 488, pp. 134-38.

25. F.N. Rhines, W.A. Johnson, and W.A. Anderson: Trans. AIME, 1942, vol. 147, pp. 205-21.

26. D.B. Williams and C.B. Carter: Transmission Electron Microscopy: A Textbook for Materials Science, Springer, New York, 2009, pp. 188-89.

27. H.H. Liebermann: J. Cryst. Growth, 1984, vol. 70, pp. 497-506.

28. J. Goldstein, D.E. Newbury, D.C. Joy, C.E. Lyman, P. Echlin, E. Lifshin, L. Sawyer, and J.R. Michael: Scanning Electron Microscopy and X-Ray Microanalysis, 3rd ed., Kluwer Academic/Plenum Publishers, New York, 2003, pp. 525-28.

29. M. Klinger and A. Jäger: J. Appl. Crystallogr., 2015, vol. 48, pp. 2012-18.

30. S. Ohtsuka, S. Ukai, M. Fujiwara, T. Kaito, and T. Narita: $J$. Nucl. Mater., 2004, vols. 329-33, pp. 372-76.
31. R. Klueh, P. Maziasz, and I. Kim: J. Nucl. Mater., 2002, vol. 311, pp. 773-77.

32. C.A. Williams, P. Unifantowicz, N. Baluc, G.D.W. Smith, and E.A. Marquis: Acta Mater., 2013, vol. 61, pp. 2219-35.

33. M. Nanko, M. Sato, K. Matsumaru, and K. Ishizaki: in Nov. Mater. Process. by Adv. Electromagn. Energy Sources, Elsevier Ltd, Osaka, 2005, pp. 281-84.

34. X. Boulnat, D. Fabrègue, M. Perez, S. Urvoy, D. Hamon, and Y. de Carlan: Powder Metall., 2014, vol. 57, pp. 204-11.

35. W. Yucheng and F. Zhengyi: Mater. Sci. Eng. B, 2002, vol. 90, pp. 34-7.

36. H. Kim, M. Kawahara, and M. Tokita: J. Japan Soc. Powder Powder Metall., 2000, vol. 47, pp. 887-91.

37. X. Boulnat, M. Perez, D. Fabregue, T. Douillard, M.H. Mathon, and Y. De Carlan: Metall. Mater. Trans. A Phys. Metall. Mater. Sci., 2014, vol. 45, pp. 1485-97.

38. C.C. Eiselt, M. Klimenkov, R. Lindau A. Möslang H.R.Z. Sandim A.F. Padilha D. Raabe : J. Nucl. Mater., 2009, vol. 385, pp. 231-35.

39. I. Hilger, F. Bergner, and T. Weissgarber: J. Am. Ceram. Soc., 2015, vol. 98, pp. 3576-81.

40. C. Cayron, E. Rath, I. Chu, and S. Launois: J. Nucl. Mater., 2004, vol. 335, pp. 83-102.

41. N. Sallez, X. Boulnat, A. Borbély, J.L. Béchade, D. Fabrègue, M. Perez, Y. De Carlan, L. Hennet, C. Mocuta, D. Thiaudière, and Y. Bréchet: Acta Mater., 2015, vol. 87, pp. 377-89.

42. F.J. Humphreys and M. Hatherly: Recrystallization and Related Annealing Phenomena, Elsevier Science Ltd, Oxford, 1995, pp. 11-14.

43. T. Muroga, T. Nagasaka, Y. Li, H. Abe, S. Ukai, A. Kimura, and T. Okuda: Fusion Eng. Des., 2014, vol. 89, pp. 1717-22.

44. Z. Oksiuta, A. Ozieblo, K. Perkowski, M. Osuchowski, and M. Lewandowska: Fusion Eng. Des., 2014, vol. 89, pp. 13741.

45. P. Unifantowicz, Z. Oksiuta, P. Olier, Y. De Carlan, and N. Baluc: Fusion Eng. Des., 2011, vol. 86, pp. 2413-16.

46. Z. Oksiuta, P. Olier, Y. de Carlan, and N. Baluc: J. Nucl. Mater., 2009, vol. 393, pp. 114-19. 